\title{
Out of sight: aggregations of epizoic comb jellies underneath mushroom corals
}
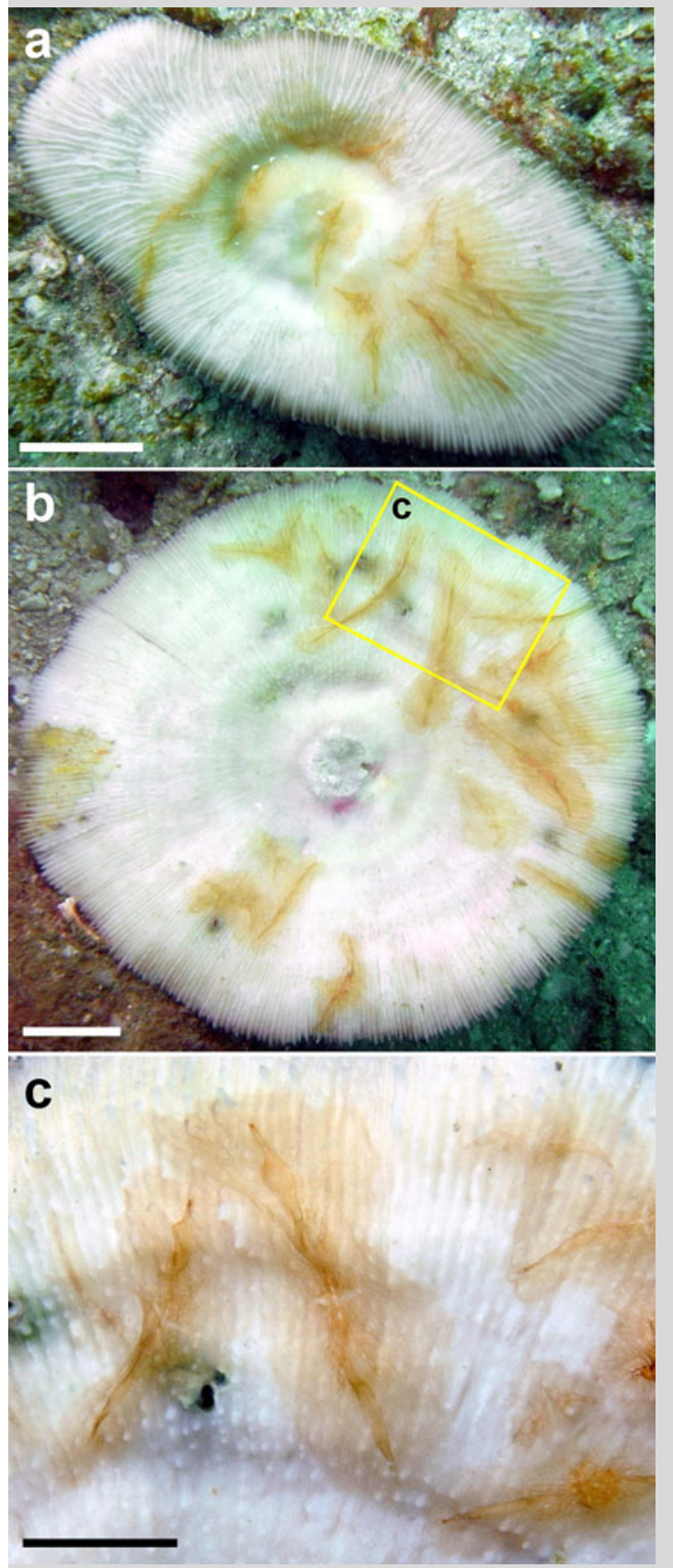

Fig. 1 Overturned mushroom corals with coeloplanid aggregations at Payar Island. a Pleuractis moluccensis with nine individuals. b Fungia fungites showing 15 coeloplanids (square indicates position of close-up in $\mathbf{c})$. $\mathbf{c}$ Close-up of area marked in $\mathbf{b}$ demonstrating shifted positions. Scale bars $2 \mathrm{~cm}(\mathbf{a}, \mathbf{b})$ and $1 \mathrm{~cm}(\mathbf{c})$
Over two-thirds of all known species of comb jellies (Ctenophora) are planktonic, whereas the remainder (order Platyctenida) is composed of benthic species. Many of these are epizoic, some of which (Coeloplana spp.) are on octocorals (Matsumoto and Gowlett-Holmes 1996; Song and Hwang 2010), but none have been reported in association with scleractinians (Stella et al. 2011; Hoeksema et al. 2012).

During a biodiversity survey around Payar Island $\left(06^{\circ} 03^{\prime}-06^{\circ} 04^{\prime} \mathrm{N}, 100^{\circ} 02^{\prime}-\right.$ $100^{\circ} 03^{\prime} \mathrm{E}$ ), Strait of Malacca, Malaysia, in June 2013, aggregations of an epizoic ctenophore of the family Coeloplanidae, possibly a Coeloplana sp., were discovered at 9-12 $\mathrm{m}$ depth. They were found on 10 free-living mushroom corals (Scleractinia: Fungiidae) belonging to Pleuractis moluccensis and Fungia fungites. Each coral hosted from two to over 20 of these coeloplanids, which showed a brown, transparent colouration (Fig. 1). Comb jellies on the white, aboral side of fungiids were more common and easier to spot than those on the brown (zooxanthellate) oral side. Some shifted their position after their host was overturned (Fig. 1b, c).

Similar associations were noted in Eilat (Israel), Sabah (Malaysia), and South Sulawesi (Indonesia) and involved the fungiids Ctenactis echinata, Cycloseris costulata, Herpolitha limax (with 20 comb jellies), and Lithophyllon repanda (A. Alamaru and B. W. Hoeksema pers obs). Our observations suggest that this benthic ctenophore may be widespread and locally abundant in the Indo-West Pacific, but that its hidden mode of life had previously kept it in obscurity.

Acknowledgments Research permission was granted by the Economic Planning Unit and the Department of Marine Parks, Malaysia.

\section{References}

Hoeksema BW, van der Meij SET, Fransen CHJM (2012) The mushroom coral as a habitat. J Mar Biol Assoc UK 92:647-663

Matsumoto GI, Gowlett-Holmes KL (1996) Coeloplana scaberiae sp. nov., a new benthic ctenophore (Ctenophora: Platyctenida: Coeloplanidae) from South Australia. Rec S Aust Mus (Adel) 29:33-40

Song JI, Hwang SJ (2010) A new species of genus Coeloplana (Ctenophora: Tentaculata: Platyctenida) from Korea. Korean J Syst Zool 26:27-221

Stella JS, Pratchett MS, Hutchings PA, Jones GP (2011) Coral-associated invertebrates: diversity, ecology importance and vulnerability to disturbance. Oceanogr Mar Biol Annu Rev 49:43-104

B. W. Hoeksema $(\bowtie) \cdot$ Z. Waheed

Department of Marine Zoology, Naturalis Biodiversity Center, P.O. Box 9517, 2300 RA Leiden, The Netherlands

e-mail: bert.hoeksema@naturalis.nl

\section{Z. Waheed}

Borneo Marine Research Institute, Universiti Malaysia Sabah, Jalan UMS, 88400 Kota Kinabalu, Sabah, Malaysia

\section{A. Alamaru}

Department of Zoology, George S. Wise Faculty of Life Sciences, Tel Aviv University, 69978 Tel Aviv, Israel 